\title{
Expressive verb morphology deficits in Arabic-speaking children with Developmental Language Disorder
}

Article

Accepted Version

Taha, J., Stojanovik, V. and Pagnamenta, E. (2021) Expressive verb morphology deficits in Arabic-speaking children with Developmental Language Disorder. Journal of Speech Language and Hearing Research, 64 (2). pp. 561-578. ISSN 1558-9102 doi: https://doi.org/10.1044/2020_JSLHR-19-00292 Available at https://centaur.reading.ac.uk/93832/

It is advisable to refer to the publisher's version if you intend to cite from the work. See Guidance on citing.

To link to this article DOI: http://dx.doi.org/10.1044/2020_JSLHR-19-00292

Publisher: ASHA

All outputs in CentAUR are protected by Intellectual Property Rights law, including copyright law. Copyright and IPR is retained by the creators or other copyright holders. Terms and conditions for use of this material are defined in the End User Agreement.

www.reading.ac.uk/centaur 
Central Archive at the University of Reading

Reading's research outputs online 
1 Expressive Verb morphology deficits in Arabic-speaking children with Developmental

2 Language Disorder

3

Keywords: Developmental Language Disorder, Specific Language Impairment, verb morphology, cross-linguistic, Arabic

6

7 Authors

8 Juhayna Taha ${ }^{1,2}$

9 Vesna Stojanovik ${ }^{1}$

10 Emma Pagnamenta ${ }^{1}$

11

$12{ }^{1}$ School of Psychology and Clinical Language Sciences, University of Reading, Reading, 13 United Kingdom.

$14{ }^{2}$ Department of Audiology and Speech Therapy, Birzeit University, Ramallah, Palestinian 15 Territories.

16

17 Address correspondence to Juhayna Taha, University of Reading, School of Psychology

18 and Clinical Language Sciences, Early Gate Reading RG6 6AL, United Kingdom.

19 E-mail: j.taha@pgr.reading.ac.uk

20

21 Funding statement: This work was funded by [REMOVED FOR REVIEW] awarded to the 22 first author.

23 Conflict of Interest Statement: The authors report no conflict of interest. 


\section{Abstract}

\section{Purpose}

27 This study investigated the production of tense and subject-verb agreement in Palestinian

28 Arabic-speaking children with Developmental Language Disorder (DLD) in comparison to their typically developing peers (TD) in terms of (1) performance accuracy and (2) error patterns.

\section{Method}

Participants were 14 children with DLD aged 4;0 - 7;10 (years; months) and 32 TD children aged 3;0-8;0 (years; months) matched on non-verbal abilities. Children were asked to complete a picture-based verb elicitation task. The task was designed to measure the production accuracy of tense and subject-verb agreement inflections in Arabic.

\section{Results}

37 The DLD group scored significantly lower than the TD group on the verb elicitation task. The DLD group was significantly less accurate than the TD group in marking tense, specifically present tense. They were also less accurate in marking agreement in general, with specific difficulty in using feminine verb forms. The DLD and TD groups differed in their tense error patterns, but not in agreement error patterns.

\section{Conclusion}

The acquisition of verb morphology in Palestinian Arabic-speaking children with DLD appears to be delayed and possibly different from their TD peers. The DLD group found the production of marked verb forms more challenging than less marked ones. These results are discussed in light of the structural characteristics of Arabic. Future studies would need to include larger sample sizes, investigate other aspects of verb morphology, including both production and comprehension, include other language domains, and consider longitudinal designs to provide more in-depth knowledge of Arabic language acquisition. 
Introduction

Children with Developmental Language Disorder (DLD) exhibit morpho-syntactic deficits often related to the use of tense and subject-verb agreement inflections (for a review, see Leonard, 2014). Production of verb inflections, such as past tense $-e d$, present third-person singular $-s$, auxiliary and copula be and auxiliary $d o$ forms have been reported as problematic for English-speaking- children with DLD (e.g., Leonard \& Kueser, 2019; Rice \& Wexler, 1996) and verb morphology difficulties are considered to be a clinical marker of DLD in English (e.g., Bedore \& Leonard, 1998; Conti-Ramsden, Botting, \& Faragher, 2001).

Cross-linguistic research shows that verb morphology is differentially impaired across languages. For example, children with DLD acquiring Germanic languages are reported to be less accurate than their typically developing (TD) peers in marking tense and agreement, and especially past tense marking (Krok \& Leonard, 2015), yet their accuracy of using verb inflections is higher than that reported for English-speaking children with DLD (for a review, see Leonard, 2014). For children with DLD acquiring Romance languages, such as Spanish and Italian, verb morphology is not as problematic; the main difficulties seem to be using function words, such as articles, and unstressed direct object pronouns (e.g., Bedore \& Leonard, 2001; Bortolini, Caselli, \& Leonard, 1997). Hebrew-speaking children with DLD have difficulties marking agreement in past tense, but not marking present tense (e.g., Dromi, Leonard, Adam, \& Zadunaisky-Ehrlich, 1999; Leonard \& Dromi, 1994).

In summary, verb morphology deficits vary between languages, especially when languages are typologically different. Therefore, studies of grammatical morphology should be languagespecific. The present study aims to extend this line of research by characterizing verb morphology deficits in children with DLD acquiring Palestinian Arabic (PA). 
In the Arab world, Modern Standard Arabic (MSA) is the language of literacy tasks and is used in formal contexts, such as news. A unique feature of the Arabic language is diglossia (Haeri, 2000). Each Arab country has a distinctive dialect of Arabic that is used for everyday social interactions. This paper focuses on the colloquial dialect of Palestine: Palestinian Arabic (PA).MSA and its dialectal varieties are characterized by their nonconcatenating templatic morphology that is based on a system of roots and patterns (McCarthy \& Prince, 1988; Ryding, 2005). The root is an invariable sequence of three to five consonants and it carries lexical meaning. The pattern consists of one or more vowels and it carries grammatical meaning. Patterns (vocalic infixes) are discontinuously inserted within the consonantal root to form words and stems (Tucker, 2011). In PA, for example, the root $d r s$ denotes a meaning of "studying". By shifting different patterns and consonantal affixes around this root we can derive different words such as daras "he studied", madrasa "school" or dars "lesson". MSA is null-subject language and verbs are conjugated to represent different grammatical categories including tense and aspect (past/present and perfective/imperfective), number (singular, dual and plural), person (first, second and third), gender (masculine and feminine), mood (indicative, subjunctive, jussive, energetic and imperative) and voice (passive/active; Benmamoun, 2000).

Three verb forms are distinguished by traditional Arabic grammarians: perfective, imperfective and the imperative verbs. There is debate of whether Arabic verbs are considered to be tense-specific where perfective and imperfective verbs refer to past and non-past actions, respectively; or aspect-specific where perfective and imperfective verbs refer to complete or non-complete actions (for a review, see Ouali, 2018). According to Ouali (2018), there seems to be a consensus in recent literature that Arabic is tense language. Table 1 presents the verb paradigm in PA. 
Table 1. Verb paradigm in Palestinian Arabic for the root d-r-s (studying)

\begin{tabular}{|c|c|c|c|c|c|c|c|c|c|c|c|}
\hline \multirow[b]{2}{*}{ Person } & \multirow[b]{2}{*}{ Number } & \multirow[b]{2}{*}{ Gender } & \multicolumn{3}{|c|}{ Past tense } & \multicolumn{3}{|c|}{ Present tense } & \multicolumn{3}{|c|}{ Imperative } \\
\hline & & & Form & Affixes & $\begin{array}{l}\text { Verb + } \\
\text { Affixes }\end{array}$ & Form & Affixes & $\begin{array}{l}\text { Verb + } \\
\text { Affixes }\end{array}$ & Form & Affixes & $\begin{array}{l}\text { Verb + } \\
\text { Affixes }\end{array}$ \\
\hline 1 & Singular & neutral $^{*}$ & 1 & $-i t$ & darasit & 9 & $b-a-$ & badrus & & & \\
\hline 1 & Plural & neutral & 2 & $-n a$ & darasna & 10 & $b-n i-$ & bnidrus & & & \\
\hline 2 & Singular & Masculine & 3 & $-i t$ & darasit & 11 & $b-t i-$ & btidrus & 17 & $P i-$ & Pidrus \\
\hline 2 & Singular & Feminine & 4 & $-t i$ & darasti & 12 & $b-t i--i$ & btidrusi & 18 & $P i--i$ & Pidrusi \\
\hline 2 & Plural & neutral & 5 & $-t u$ & darastu & 13 & $b-t i--u$ & btidrusu & 19 & $P i--u$ & Pidrusu \\
\hline 3 & Singular & Masculine & 6 & $\varnothing$ & daras & 14 & $b-y i-$ & byidrus & & & \\
\hline 3 & Singular & Feminine & 7 & $-a t$ & darsat & 15 & $b-t i-$ & btidrus & & & \\
\hline 3 & Plural & neutral & 8 & $-u$ & darasu & 16 & $b-y i--u$ & byidrusu & & & \\
\hline
\end{tabular}

Note. "The gender category "neutral" indicates that the affix attached to the verb has no gender distinction. 


\section{Past Tense}

115 In PA, the perfective verb is used to refer to past and completed actions (Abu-Ghazaleh, 116 1983, p.125), will be referred to as past tense. Past tense is an abstract morpheme, i.e. not

117 realized by an overt affix (Benmamoun, 2000). The past tense verb consists of a stem daras 118 (root + vocalic infixes) and takes only suffixes which denote subject-verb agreement 119 (Benmamoun, 2000). The suffix is a discontinuous unit which simultaneously reflects 120 agreement for person, gender and number. For example, the suffix - $t i$ in darasti "you studied" 121 denotes agreement for a $2^{\text {nd }}$ person feminine singular subject (form 4 , Table 1 ). The $3^{\text {rd }}$ person 122 masculine singular daras " he studied" is unmarked, i.e. it does not take any suffixes (form 6,

123 Table 1).It is homonymous with the past tense verb stem. It is important to note here that unlike 124 MSA, PA verb paradigm is smaller as the subject-verb number agreement has no dual category and the plural agreement suffix $-u$ has no gender distinction (e.g., forms 8,16 and 19 in Table 1; Jarrar et al., 2014).

\section{Present tense}

128 The imperfective verb is used to refer to an ongoing activity which could be in the present, past 129 or the future time (Benmamoun, 2000). In PA, the imperfective verb has three moods: 130 indicative, subjunctive and imperative (Abu-Ghazaleh, 1983; Shahin, 2007). In this section, 131 we focus on its indicative mood which occurs in sentences with present tense interpretation 132 (henceforth, present tense).

133 The present tense is composed of a stem drus (root + vocalic affix) with its subject-verb 134 agreement being realized by a prefix or a combination of a prefix and a suffix (circumfix morpheme). In the PA present tense verb, the temporal information is carried by the present progressive clitic $b$-, which attaches to the prefix (Abu-Ghazaleh, 1983; Jarrar et al., 2014;

137 Shahin, 2007). Person agreement is mainly realized by the prefix. Gender is also realized by 138 the prefix, except for the $2^{\text {nd }}$ person singular feminine where gender is expressed by the suffix 
$139-i$ (form 12, Table 1). Plural number agreement is realized by the suffix $-u$ except for the $1^{\text {st }}$

140 person where the number is realized by the prefix bni- (Benmamoun, 2000). More than one

141 subject-verb agreement feature can be realized by one prefix. For instance, the prefix byi- in

142 byid.rus "he is studying" indicates a $3^{\text {rd }}$ person masculine subject (person and gender

143 agreement). In other instances, the subject-verb agreement features are realized by a circumfix

144 affix, an unanalyzable unit of a prefix and a suffix. An example is the circumfix byi- $u$ in

145 byid.ru.su "they are studying", where it denotes $3^{\text {rd }}$ person plural agreement (no gender

146 distinction).

147 Finally, it is clear that the verb forms we described differ from each other in terms of

148 markedness, i.e. the morphological realization of grammatical categories (e.g., Corbett, 1991,

149 2000; Leech, 2006). In Arabic subject-verb agreement, contrasts in number agreement

150 (singular versus plural) and gender agreement (masculine versus feminine) are asymmetrical

151 in terms of their morphological realization. Rather, one member of the contrast is overtly coded

152 by an affix and therefore is "marked", whereas the other member has no overt coding (zero

153 affixes) and is therefore considered as an unmarked form. For example, if we look at the opposition of singular-plural in number agreement, the singular verb is not overtly realized by any affixes (e.g., daras "he studied"), whereas, the plural verb is realized by the affix $-u(e . g$., darasu "they studied"). The singular verb is therefore considered as the unmarked/default

157 form, while the plural is the marked form. The same applies to gender agreement (only in past 158 tense) where the feminine verb is marked whereas the masculine form is unmarked.

159 The Imperative

Although the imperative verb has a shared structure with the present tense, the imperative

162 lacks the present progressive clitic $b$ - and the initial prefix which indicates person and gender

163 agreement. The imperative only occurs in the second person, yet the person feature is unmarked (Al-Aqarbeh, 2011). Although PA has a prefix for second person present tense verbs 
(e.g., bti- or bit-), this prefix is dropped in the imperative verb. Gender and number agreement of the imperative verb is denoted by the suffix (see forms $17-19$, Table 1).

There is little agreement on whether the default tense form in Arabic. While some researchers augured that the default form is the imperative (Abdallah \& Crago, 2008; Morsi, 2009; Omar, 1973; Qasem \& Sircar, 2017), others identify it as the imperfective verb stem (Aljenaie, 2010; Benmamoun, 1999). Fahim (2017) stated that the default verb can take more than one form including the imperative, subjunctive or a variant of the imperfective verb stem. The imperative does not have a time reference and it is considered non-finite (Ryding, 2005). Similarly, Benmamoun (2000) states that the imperfective verb occurs in different contexts such as sentences with past, present or future interpretation as well as in embedded non-finite sentences. This evidence clearly shows that the imperfective does not morphologically carry any temporal or aspectual information (Benmamoun, 1999, 2000). Although there are slight morphological differences between the two forms (primarily in their prefixes), they are very similar which could be the cause of inconsistency among studies. By removing the affixes of the imperative (e.g., form 17, Table 1) and imperfective indicative (present tense; e.g., form 11, Table 1), it can be seen that both forms share the same stem, suggesting that the imperative is derived from the imperfective verb (Benmamoun, 1999; Shahin, 2010; Soltan, 2007).

\section{Typical and atypical verb morphology acquisition in Arabic}

Few studies have examined typical language acquisition in Arabic. In a longitudinal study, Omar (1973) described the acquisition of phonology, syntax, and morphology in 37 Egyptian Arabic-speaking children aged 6 months to 15 years. The study reported that children started using verbal agreement morphology around the age of 2;3 years. Masculine and singular verbs emerged earlier than feminine and plural verbs, respectively. Omar (1973) further observed 
that, in the early stages of verb production, Egyptian Arabic-speaking children predominantly used the singular masculine verb as the default verb agreement category.

192 development of their two children from around the age of one year up until six years. Their 193 data on the acquisition of verbs indicated a certain order in which verb forms emerge in PA. In

194 line with Omar (1973)'s findings on verb agreement, masculine and singular verbs were developed earlier than feminine and plural verbs, respectively. Additionally, 3rd person verbs appeared before 1 st person verbs, with $2^{\text {nd }}$ person verbs appearing last. This order was limited to past tense verbs, as no particular order was noted for present tense verbs.

198 Similar findings are reported by Aljenaie (2001) who followed the development of verb 199 tense and agreement in four Kuwaiti Arabic-speaking children aged 1;17 to 2;6 years for 6 months using spontaneous speech, elicited production and imitation tasks. All four children began using present and past tense verbs at age 2;0 years. However, the order at which these forms emerged in the children's language could not be determined due to the variability in the data. Agreement marking emerged in a developmental pattern: masculine verbs appeared before feminine verbs, singular verbs appeared before plural verbs while 1 st person verbs appeared first followed by $3^{\text {rd }}$ person and $2^{\text {nd }}$ person verbs, respectively. Furthermore, Aljenaie (2001) noted that children showed a tendency to use unmarked forms in contexts where verb infections where required. In past tense contexts, the unmarked form was the $3^{\text {rd }}$ person masculine singular, wherein the present tense context the unmarked form was described as

209 being as either the imperative masculine verb or a form that was homophonous to the stem of 210 the target verb (Aljenaie, 2001). The use of the imperative was also noted in the speech of

211 typically developing Yemini (Qasem \& Sircar, 2017) and Egyptian-Arabic-speaking children 212 (Omar, 1973). 
213 In another longitudinal study, Aljenaie (2010) examined spontaneous speech samples of

214 three Kuwaiti Arabic-speaking children aged 1;8 to 3;1 years. An analysis of agreement errors

215 revealed that masculine verbs were used to substitute feminine verbs. These findings suggest

216 that children show a preference for the less marked, more neutral masculine form, over the

217 feminine counterpart, which is strongly and consistently marked by inflections for gender

218 (Aljenaie, 2010, p.852). Regarding tense errors, Kuwaiti Arabic-speaking children used the

219 imperfective bare verb, a non-finite form, in place of fully inflected verbs (Aljenaie, 2001,

220 2010). This supports the view that the imperfective verb stem is most likely the default tense

221 form in Arabic (Benmamoun, 1999, 2000).

Basaffar and Safi (2012) investigated the developmental patterns of tense and verb agreement in two to four-year-old Hijazi Arabic-speaking children. Using experimental tasks alongside a spontaneous speech analysis, they replicated the findings of verb agreement reported by Aljenaie (2001). Basaffar and Safi (2012) concluded that children produced present and imperative forms with higher accuracy than past and future forms. However, the lack of any reported accuracy levels, statistical analysis, error analysis or clear guidelines for the protocol and scoring of the children's responses limits the generalizability of these results.

Research into morpho-syntactic difficulties in Arabic-speaking children with DLD has been scarce. Drawing on her dissertation data from 2002 (Abdallah, 2002), Abdallah and Crago (2008) analyzed speech samples obtained from Hijazi-Arabic speaking children with DLD 4;0 to 5;3 years of age. Children with DLD were less accurate than their age and language-matched peers in marking tense in general. The DLD group scored significantly higher for past tense than for present tense forms, which suggests that these children's difficulties with tense were more pronounced in present tense verbs. Not all subject-verb agreement categories were

236 problematic for the DLD group. Present tense, feminine and $3^{\text {rd }}$ person verbs, which were 237 structurally more complex were more problematic than unmarked verb forms, such as past 
tense and masculine verb forms (Abdallah \& Crago, 2008). Importantly, both TD and DLD children used the imperative in place of the target tensed forms. In a few instances, children used an incorrect tense form (e.g., present tense for past tense). When agreement errors occurred, one agreement feature was affected (e.g., third person masculine singular replaced third person feminine singular). Abdallah and Crago (2008) characterized agreement errors as follows: singular verbs were used in place of plural verbs, masculine verbs for feminine verbs and first person verbs for third person verbs.

Morsi (2009) found that Egyptian Arabic-speaking, 6-year old children with DLD were less accurate than their age and language-matched peers in the production of verbal tense and agreement, with tense being more challenging than agreement. Morsi (2009) stated that, for the DLD group, present tense production was more difficult than past tense production, and the imperative was used as the default form when tense errors occurred.

Drawing on her dissertation data from 2005 (Fahim, 2005), Fahim (2017) analyzed spontaneous speech samples of three Egyptian Arabic-speaking children with DLD 3;1 to 4;6 years of age and six TD children aged $1 ; 0$ to $4 ; 0$ years. She concluded that only subject-verb agreement marking was impaired in Egyptian-speaking children with DLD while tense marking was less affected (based on past tense marking). Furthermore, Fahim (2017) identified three errors patterns that were noted in the speech of children with and without DLD. The first error pattern involved the use of a default verb form in place of the tensed verb. The form was described to resemble the imperative or the subjunctive. The second error pattern involved a verb with the correct tense but incorrect agreement. The third error involved the production of non-adult target forms (pseudowords) in place of the target verbs. Qatari Arabic-speaking children with DLD (aged 4;6 to 9;4 years) were less accurate in producing tense and agreement inflections than TD children. Specifically, past tense was more 
263 problematic than present tense for the DLD group. Shaalan (2010) stressed that these results

264 were preliminary, as they were only based on a few items $(N=12)$ and noted that further 265 research was required.

266 The results of the Arabic studies have generally determined tense and verb agreement 267 aspects that are challenging for children with DLD. There is little agreement among the studies 268 on which aspect of verb morphology is more problematic for children with DLD: tense or agreement. Also, it is inconclusive what the default form in Arabic is as both the imperative and the imperfective bare verb forms have been suggested These questions require further investigation. Besides, two other methodological issues may have contributed to different findings. First, low participants numbers $(N=3)$ in Fahim's (2017) and Morsi's (2009) studies, which does not allow for generalization of their results. Second, methodological differences in terms of task used: Abdallah and Crago's (2008) and Fahim's (2017) studies analyzed speech samples, whereas Morsi (2009) and Shaalan (2010) used a structured elicitation task for the target verb inflections. This could have resulted in differences in the number and type of verb inflections included in the analyses.

\section{Aims and Approach}

This study aims to extend previous Arabic studies by conducting a systematic investigation of verb morphology use by children with and without DLD acquiring Palestinian Arabic (PA). Determining which verb forms are potential linguistic markers of DLD in PA would inform and enhance the current assessment practices of DLD in Palestine. Furthermore, data from Arabic children with DLD could be used to examine the assumptions of theoretical accounts of DLD and provide insights into possible underlying mechanisms of the disorder.

The present study examined the production of tense and subject-verb agreement in PAspeaking children with DLD as compared with typically developing (TD) children by 
investigating: 1) the production accuracy and 2) error patterns of verb tense and agreement marking.

We predict that, compared to TD children, children with DLD will achieve lower overall accuracy on the verb elicitation task. Children with DLD will have more difficulties using marked verb forms compared to less marked ones. Specifically, the use of present tense verbs is expected to be more challenging than past tense verbs (Abdallah \& Crago, 2008; Fahim, 2005; Morsi, 2009). Feminine and plural verbs are predicted to be more problematic than masculine and singular verbs forms (Abdallah \& Crago, 2008). Children with and without DLD will use the imperative verb (Abdallah \& Crago, 2008; Fahim, 2017; Morsi, 2009) or the imperfective bare verb as tense default forms (Aljenaie, 2010; Benmamoun, 1999). Finally, children with and without DLD will use less marked verbs (masculine and singular verbs) as default agreement forms in place of more marked, feminine and plural verbs (Abdallah \& Crago, 2008; Aljenaie, 2010).

\section{Methods}

\section{Participants}

The study was approved by the Research Ethics Committee at [REMOVED FOR REVIEW]. Sixty-four Palestinian Arabic-speaking children were recruited: 14 children with DLD (10 boys), aged between 48 and 94 months with a mean age of 66 months $(S D=15.47)$ and 32 TD children (19 boys), aged between 36 and 96 months with a mean age of 62 months $(S D=16.88)$. The groups did not differ significantly on chronological age $(t(44)=.83, p=.413$, $d=.27)$. The TD and DLD groups were matched on non-verbal cognitive abilities as measured by raw score on the Coloured Progressive Matrices (CPM; Ravens, 2007), as this test is not standardized on PA-speaking children $t(42)=-.81, p=.423, d=.26$, variance ratio $=1.11)$.

310 Table 2 summarizes the raw scores of the two groups on several background measures. See 311 Appendix 1 for individual scores. 
Table 2. A summary of the demographic characteristics, developmental milestones and background measures for the TD and DLD groups

\begin{tabular}{|c|c|c|}
\hline & \multicolumn{2}{|c|}{ Group } \\
\hline & $\begin{array}{c}\text { TD } \\
\mathrm{N}=32\end{array}$ & $\begin{array}{l}\text { DLD } \\
N=14\end{array}$ \\
\hline Demographic characteristics & \multicolumn{2}{|c|}{$\%(N)$} \\
\hline \multicolumn{3}{|l|}{ Mother's education } \\
\hline Primary school & $9.38(3)$ & $14.29(2)$ \\
\hline High school & $31.25(10)$ & $28.57(4)$ \\
\hline University /college degree & $46.87(15)$ & $35.74(5)$ \\
\hline Postgraduate degree & $12.5(4)$ & $21.43(3)$ \\
\hline Working mother & $39.47(15)$ & $50(7)$ \\
\hline $\begin{array}{c}\text { Family history of } \\
\text { communication disorders }\end{array}$ & $6.25(2)$ & $42.56(6)^{*}$ \\
\hline $\begin{array}{c}\text { Developmental milestones } \\
\text { Age in months }\end{array}$ & \multicolumn{2}{|c|}{$\operatorname{Mean}(S D)$} \\
\hline First word & $\begin{array}{c}12.69(2.46) \\
9-18\end{array}$ & $\begin{array}{c}24.64(6.65)^{*} \\
15-36\end{array}$ \\
\hline Follow simple commands & $\begin{array}{c}17.59(3.44) \\
12-24\end{array}$ & $\begin{array}{c}20.14(5.95) \\
12-36\end{array}$ \\
\hline walking & $\begin{array}{c}12.66(1.45) \\
10-15\end{array}$ & $\begin{array}{c}12.5(1.7) \\
10-16\end{array}$ \\
\hline $\begin{array}{c}\text { Background measures } \\
\text { raw scores }\end{array}$ & \multicolumn{2}{|c|}{$\operatorname{Mean}(S D)$} \\
\hline$M P U$ & $\begin{array}{l}4.91(1.24) \\
2.41-7.61\end{array}$ & $\begin{array}{l}3.58(1.04)^{* * * *} \\
2.19-6.27\end{array}$ \\
\hline $\begin{array}{r}C L-N W R \\
\text { (out of 30) }\end{array}$ & $\begin{array}{c}26.84(4.34) \\
16-30\end{array}$ & $\begin{array}{c}15.57(4.13)^{* *} \\
9-23\end{array}$ \\
\hline $\begin{array}{c}C P M \\
\text { (out of } 36 \text { ) }\end{array}$ & $\begin{array}{c}16.67(4.39) \\
8-23\end{array}$ & $\begin{array}{l}15.5(4.62) \\
9-23\end{array}$ \\
\hline
\end{tabular}

Note. TD = Typically Developing. DLD = Developmental Language Disorder. $\mathbf{S D}=$ standard deviation. $\mathbf{M P U}=$ Mean Morpheme per Utterance. $\mathbf{C L}-\mathbf{N W R}=$ Cross linguistic Non-word Repetition. CPM $=$ Colored Progressive Matrices. ${ }^{*}=\mathrm{p}<.05,{ }^{* * *}=p<.01,{ }^{* * * *}=p<.001$ 
315 Children with DLD were recruited through four private speech therapy clinics located in 316 [REMOVED FOR REVIEW]. They were previously independently diagnosed with DLD by 317 qualified speech and language therapists (SLTs) who used non-standardized assessment tasks.

318 Based on a screening of clinical reports, all children in this group had primary language deficits,

319 no obvious non-verbal difficulties, used speech as their primary means of communication and 320 had no diagnoses of any speech disorder interfering with intelligibility. All children were receiving language intervention services at the time of the study. The TD control children were recruited through one day-care, two kindergartens and one school in [REMOVED FOR REVIEW] and had no reported history of language delay/impairment and demonstrated ageappropriate language skills as determined by parental/teachers' reports.

Parents completed a questionnaire that included questions about demographics (e.g. maternal education), child's health and general development, language acquisition milestones and family history of language difficulties. The questionnaire was used to ensure that all children were monolingual Arabic speakers and had no evidence or reported history of hearing loss, cognitive and/or neurological impairments, speech motor disorders and diagnoses of other developmental disorders (e.g., Autism). Based on questionnaire results, alongside teacher reports, four children did not meet the eligibility criteria for the TD group and were not tested for the study.

Groups did not differ significantly in maternal education: $\chi^{2}(3, N=46)=1.03, p=.793$.

334 Children with DLD had a significantly higher frequency of family history of communication 335 disorders: $\left.\chi^{2}(1, N=46)=6.72, p<.001\right)$ and produced their first words significantly later: $t(14.57)=6.53, p<.001, d=2.39$. See Table 2 for details. assessments, scores on standardized language assessments were not available. Two non- 
standardized tasks were used to verify that children with DLD had language skills that were considerably below the level expected for their chronological age.

1. Spontaneous narratives of 100 utterances were elicited using a wordless picture book "Frog, where are you" (Mayer, 1969) to calculate the Mean Morpheme per Utterance (MPU). MPU is equivalent to the Mean Length of Utterance (MLU; Brown, 1973) in English. MPU is a measure of grammatical development and takes into account the highly synthetic nature and rich morphology of Semitic languages. (Dromi \& Berman, 1982). MPU is calculated by diving the total number of morphemes by the total number of utterances produced in the narrative task. We followed the guidelines of counting Arabic morphemes that were developed by Shaalan and Khater (2006). These guidelines were adapted from the MPU calculation rules in Hebrew (Dromi \& Berman, 1982). Previous studies on Arabic (Abdallah \& Crago, 2008; Shaalan, 2010) have also used this measure to confirm the presence of developmental language impairment.

2. The Arabic version of a Crosslinguistic Nonword Repetition test (CL-NWR; for a full description see Abi-Aad \& Atallah, 2012). The task includes 30 nonwords and was scored using a whole-item approach (correct/incorrect) with the maximum score being 30. The task was found to have potential for the discrimination of L1 learners of Lebanese Arabic with and without DLD (Abi-Aad \& Atallah, 2012). The task was also documented to have good diagnostic accuracy in identifying Palestinian children at risk of DLD (Taha \& Chondrogianni, 2017).

The mean MPU for the DLD group was significantly lower for the TD group: $t(44)=-3.51$, $p<.001, d=1.23$. Scores of the DLD group were also significantly lower than the TD group on the CL-NWR test: $t(44)=-8.22, p<.001, d=2.63$. Norms for these tasks are not established

362 for the Palestinian population. Therefore, mean raw scores are reported (see Table 2). 
364 An elicitation task was developed to test children's production of the following verb forms

365 (1) present masculine singular, (2) present feminine singular, (3) present plural, (4) past 366 masculine singular, (5) past feminine singular, and (6) past plural. The task assessed the 367 production of these morphemes in third person only.

368 Seventy-two pictures were divided into 30 pairs of experimental items and 12 filler items 369 (singular and plural noun pairs). The experimental items were further categorized into 8 paired 370 items for masculine singular verb forms, 7 paired items for feminine singular verb forms and 37115 paired items for plural verb forms. Because present tense inflections vary in stress 372 assignment, $50 \%$ of the present tense verbs had a stressed tense prefix and $50 \%$ had an 373 unstressed tense prefix (see Appendix 2 for test items).

374 Each verb was represented by a pair of pictures showing a sequence of events that the child 375 was asked to describe. The first photograph depicted a person or a group performing an activity and the second photograph depicted the same person or group having finished the activity. The test items depicted actions from familiar daily routines. The task was piloted with 10 TD children aged between 40 and 67 months, mean age 58 months $(S D=9.36)$ to ascertain that children of this age could easily identify the verbs in the pictures. Results showed that $96.38 \%$ $(S D=8.21)$ of the children were able to correctly name the pictures.

\section{Procedure}

382 Children were assessed individually in a quiet room within their nursery, school or speech and language therapy clinic. All assessments were conducted in one session by the first author (a qualified Arabic-speaking speech-language therapist). Each session lasted approximately 1 hour and was audio-recorded using a Sony ICD-PX370 Digital Voice Recorder. The tasks were administered in the following order: Coloured Progressive Matrices (CPM), narrative task,

387 Crosslinguistic Nonword Repetition Task (CL-NWR), and the verb elicitation task. Four 
practice items were given to familiarize the children with the verb elicitation task and items were presented in the same order for all participants. Throughout the task, children received

390 praise for their efforts but were not provided with any feedback about the accuracy of their

391 productions. The examiner pointed at each item and presented the child with a question that

392 created an obligatory context for the use of the target verb inflections in present tense, and past

393 tense as seen in the examples below:

1) Present tense

a. Researcher: ish byisawwi il-walad halla?

What do-PRES-3MS the-boy now?

'What is the boy doing now'?

b. Child:

il-walad byiyakul

buza

\section{2) Past tense}

a. Researcher: il-walad xallas,

ish sawa

il-walad? The-boy finish-PAST-3MS, what do-PAST-3MS the-boy? What did the boy do yesterday?

\section{$408 \quad$ Scoring}

409 The children's responses were transcribed orthographically online and were audio-recorded for

410 further analysis. Children's productions were scored using three methods:

411 1. Whole-item accuracy: The child's response was scored as correct if it was in the correct 412 tense and had the correct person, number and gender agreement. That is, the child's 
413 response should be identical to the target. If the response differed from the target verb in

414 any of these elements (e.g., correct tense, person and number agreement but incorrect

415 gender agreement), it was scored as incorrect. Correct response received a score of 1 while

416 incorrect verbs received a score of zero. The maximum overall score the child could

$417 \quad$ achieve on the task was 60.

418 2. Tense accuracy: Tense accuracy was determined based on the context of the picture

419 (present vs past). The child's response was scored as correct and received a score of 1 if it

420 matched the target tense, regardless of subject-verb agreement accuracy. In case of an

421 incorrect response, the substitute tense was recorded for further error analysis.

3. Subject-verb agreement accuracy: As described above, subject-verb agreement in Arabic is fusional. Therefore, determining the accuracy of subject-verb agreement is not transparent. Inspection of our data revealed the following: 1) children tended to omit different parts of the same prefix. For instance, $3^{\text {rd }}$ person masculine singular verb byidrus "he is studying" would be produced as yidrus which is a $3^{\text {rd }}$ person masculine imperfective bare verb or $i d r u s$ a $2^{\text {nd }}$ person masculine imperative verb. 2) Children treated the discontinuous circumfix $b y i-u$ of the $3^{\text {rd }}$ person plural present tense as separate affixes. Omitting part of the circumfix meant that some but not all of the agreement features of the verb were lost. For example, in the verb byidrusu "they are studying", an omission of - $u$ will only change number agreement from plural to singular. However, $3^{\text {rd }}$ person agreement will not change since the prefix byi- is preserved. To account for this pattern, we followed Abdallah and Crago (2008)'s scoring approach. Each of the agreement features of the child's response (person, number and gender) was checked against the agreement features of the target verb (subject in the picture), irrespective of tense accuracy. Each agreement category was scored as correct or incorrect. Hence, we had three scores: person agreement accuracy, number agreement accuracy and gender agreement accuracy. Errors in each 

element were recorded for further error analysis. To better illustrate the scoring system, we provide an example below.

\section{Verb + Affixes Tense Person Number Gender}

Affixes

Target btidrus bti- Present 3rd Singular Feminine

Child's idrus $\quad i^{-} \quad$ Imperative 2nd Singular Masculine

production

Accuracy Incorrect Incorrect Incorrect incorrect Correct Incorrect

Whole-item Incorrect

score

440

Reliability

442 The spontaneous speech sample of randomly selected 10 children (21\% of the sample) and 443 their responses on the verb elicitation tasks were scored by an independent speech and language 444 therapist to calculate inter-rater reliability. The agreement between the two raters was $100 \%$ 445 for the overall score, $98 \%$ for tense scores, $100 \%$ for gender scores, $100 \%$ for number scores, $44697 \%$ for the person scores. The inter-rater agreement for MPU calculations was $87 \%$.

\section{Analysis}

448 Statistical analysis was carried out using R studio software version 3.6.0 (RStudio, 2019).

449 Raw scores were converted to percentages. For each of the tense and agreement accuracy 450 scores, mixed-design ANOVAs were conducted with the target grammatical category as a 451 within-subject variable and group as the between-subject variable. Significance levels were set at $p<.05$. Significant interactions were followed by simple effects analysis.

453 Bonferroni corrections for multiple comparisons were applied (Field, 2009, p.373). Type 1 454 error was controlled for by dividing the significance value $(p<.05)$ by the number of 
comparisons $(n=4)$. Hence, the significance level for all simple effects analysis was $p<.0125$.

456 Results

457

458

460

461

462

463

464

465

466

467

468

469

470

471

472

473

474

475

476

477

478

479

\section{Analysis 1: The production accuracy of verb tense and agreement marking}

Overall, the DLD group scored significantly lower than the TD group on the verb elicitation task $(t(16.91)=-3.89, p<.001, d=1.36)$. Table 3 summarizes the accuracy of the verb forms examined in the task.

\section{Tense accuracy}

Tense accuracy scores were analyzed using a 2 x 2 mixed-design ANOVA with group as a between-subject factor (2 levels: DLD and TD) and verb tense as a within-subject factor (2 levels: past and present). Analysis revealed a significant main effect of group $[F(1,44)=22.36$, $\left.p<.001, \eta^{2}=.34\right]$, verb tense $\left[F(1,44)=23.85, p<.001, \eta^{2}=.35\right]$. Also, the group by verb tense interaction was significant $\left[F(1,44)=18.04, p<.001, \eta^{2}=.29\right]$.

The TD group were significantly more accurate marking past tense than present tense: $t(31)$ $=2.79, p<.0125, d=.49$. Similarly, the DLD group was more accurate with past tense marking than present tense marking: $t(13)=3.97, p<.0125, d=1.06$. Independent sample t-tests revealed that the TD group was more accurate than the DLD group in using present tense: $t(14.87)=-3.49, p<.0125, d=1.27)$ and past tense: $t(44)=-3.36, p<.0125, d=1.07$.

Furthermore, we examined whether the production accuracy of present tense verbs varied based on whether the prefix was stressed or not. Children with DLD used present tense verbs with a stressed prefix with $73.33 \%$ accuracy $(S D=29.12)$. This was slightly higher than their accuracy of producing verbs with unstressed prefixes which was $67.13 \%(S D=22.57)$. However, this difference was not statistically significant $(t(13)=-1.41, p=.18, d=.38)$. 
Table 3. Mean Percentages correct (with standard deviations) of the TD and DLD groups for the target morphemes

\begin{tabular}{|c|c|c|}
\hline & \multicolumn{2}{|c|}{ Group } \\
\hline & $\begin{array}{c}\text { TD } \\
\mathrm{N}=32\end{array}$ & $\begin{array}{l}\text { DLD } \\
\mathrm{N}=14\end{array}$ \\
\hline Overall accuracy & $94.64(9.06)$ & $77.14(15.71)^{* * *}$ \\
\hline Tense accuracy & $96.09(6.51)$ & $81.42(14.93)^{* *}$ \\
\hline Present tense & $94.06(9.94)$ & $70.24(24.72)^{* *}$ \\
\hline Past tense & $98.13(4.47)$ & $92.38(6.97)^{* *}$ \\
\hline Agreement accuracy & $97.34(4.86)$ & $85.12(12.75)^{*}$ \\
\hline Gender agreement & $98.96(2.15)$ & $93.10(7.33)^{*}$ \\
\hline Masculine agreement & $100.00(0)$ & $97.32(4.72)$ \\
\hline Feminine agreement & $97.77(4.6)$ & $88.27(12.09)^{* *}$ \\
\hline Number agreement & $98.7(4.55)$ & $95.36(7.11)^{* * *}$ \\
\hline Singular agreement & $100.00(0)$ & $98.81(2.48)$ \\
\hline Plural agreement & $97.40(6.21)$ & $91.91(8.54)$ \\
\hline $\begin{array}{c}\text { Person agreement } \\
3^{\text {rd }} \text { person }\end{array}$ & $99.06(2.71)$ & $92.14(10.55)^{* *}$ \\
\hline
\end{tabular}

\footnotetext{
Note. TD = Typically Developing. DLD = Developmental Language Disorder. ${ }^{*}=p<.05,{ }^{* * *}=p<.01,{ }^{* * *}=p<.001$
}

\section{Subject-verb agreement accuracy}

A composite percentage score of subject-verb agreement was calculated for number, gender, and person. Subject-verb agreement accuracy scores were analyzed using a 2 x 2 mixed-design ANOVA with group as a between-subject factor (2 levels: DLD and TD) and verb tense as a within-subject factor (2 levels: past and present). There was a main effect of group $[F(1,44)=$ 
$\left.49222.5, p<.05, \eta^{2}=.33\right]$. The main effect of tense was non-significant, but the interaction 493 between tense and group was significant $\left[F(1,44)=8.39, p<.001, \eta^{2}=.16\right]$. Based on simple 494 effects analysis, the TD group marked subject-verb agreement at a similar level of accuracy for 495 past tense $(M=97.4 \%, S D=5.53)$ and present tense $(M=97.29 \%, S D=6.07, t(31)=.09, p=$

$496.923, d=.01$. The DLD group presented a different pattern, showing higher accuracy in 497 marking subject-verb agreement in past tense verbs $(M=97.92 \%, S D=6.07)$ compared to 498 present tense verbs $(M=89.52 \%, S D=9.41): t(13)=2.36, p<.05, d=.62$. Furthermore, the

499 TD group was significantly more accurate than the DLD group in marking subject-verb 500 agreement in present tense verbs: $t(14.87)=-3.49, p<.0125, d=1.27$, but not in past tense 501 verbs: $t(17.07)=-2.92, p=.02, d=1.0$.

502

503

504

505

506

507

508

509 $510<.01, \eta 2=.18]$

511

512

513

514

515

\section{Subject-verb agreement: gender agreement accuracy}

This analysis was only conducted for singular verbs as gender in verbs that end with the plural morpheme $-u$ is used regardless of the gender of the subject in PA. Gender agreement accuracy scores were analyzed using a $2 \times 2 \times 2$ mixed-design ANOVA with group as a between-subject factor (2 levels: DLD and TD), verb tense (2 levels: past and present) and gender category (2 levels: masculine and feminine) as within-subject factors. There were significant main effects of group $\left[F(1,44)=17.36, p<.001, \eta^{2}=.28\right]$ and gender $[F(1,44)=$ 18.52, $\left.p<.001, \eta^{2}=.3\right]$. The group by gender interaction was significant $[\mathrm{F}(1,44)=9.83, \mathrm{p}$

The TD group showed higher accuracy in marking masculine verbs relative to feminine verbs: $t(31)=-2.74, p<.01, d=.49)$. The same was observed in the DLD group: $t(13)=-3.31$, $p<.0125, d=.88$. The TD group and DLD group did not differ significantly in their production accuracy of masculine verbs: $t(13)=-2.12, p=.06, d=.84)$. Yet, the DLD group was significantly less accurate than the TD group in using feminine verbs: $t(14.68)=-2.85, p<$ 
$.0125, d=1.04)$. There were no significant interactions between group and tense, gender and

517 tense, and group, gender, and tense.

518 Further analysis was conducted for the DLD group to examine whether the production

519 accuracy of the present tense feminine prefix was affected by stress assignment. The DLD

520 group produced present tense verbs with a stressed prefix $(M=78.57 \%, S D=32.31)$ with

521 significantly higher accuracy than the same forms but with unstressed prefix: $M=61.43 \%, S D$ $=29.83, t(13)=-2.28, p<.05, d=.61$.

\section{Subject-verb agreement: number agreement accuracy}

The number agreement accuracy scores were analyzed with a $2 \times 2 \times 2$ mixed-design

ANOVA with group as a between-subject factor ( 2 levels: DLD and TD), verb tense (2

subject factors. There were significant main effects of group $\left[F(1,44)=7.36, p<.01, \eta^{2}\right.$ $=.14]$ and number $\left[F(1,44)=16.76, p<.001, \eta^{2}=.28\right]$. The group by number interaction was significant $\left[F(1,44)=4.29, p<.05, \eta^{2}=.11\right]$. Simple effects analysis revealed that the TD group did not differ in the accuracy of marking singular and plural verbs: $t(31)=$ $-2.37, p<.0125, d=.42$. In contrast, the DLD group was significantly less accurate in marking plural verbs compared to singular verbs: $t(13)=-3.64, p<.0125, d=.97$. The TD and DLD groups were not significantly different in their accuracy of marking singular verbs: $t(13)=-1.79, p=.094, d=.6$ or plural verb forms: $t(19.26)=-2.44, p=.044, d=$ .74. There were no significant interactions between group and tense, number and tense, and group, number, and tense.

\section{Subject-verb agreement: person agreement accuracy}

538 Person agreement score was based on the accuracy of marking verbs in $3^{\text {rd }}$ person and were analyzed with a 2x2 mixed-design ANOVA with group as a between-subject factor ( 2 levels: 
main significant effect of group $[\mathrm{F}(1,44)=12.26, p<.001$, eta $=0.22]$, with the TD group outperforming the DLD group in person agreement accuracy. There was a main effect of tense

$543[\mathrm{~F}(1,44)=7.53, p<.05$, eta $=0.15]$. In general, marking $3^{\text {rd }}$ person in past tense verbs $(\mathrm{M}=$ $54498.62 \%, \mathrm{SD}=3.34 \%)$ was easier than marking present tense verbs $(\mathrm{M}=95.29, \mathrm{SD}=$ 545 11.06). The group by tense interaction was not significant $[\mathrm{F}(1,44)=2.72, p=.08$, eta $=0.02]$.

\section{Analysis 2: Error patterns in verb tense and agreement marking}

547 Tense

548 We compared DLD and TD children on the type and frequency of the forms they used in place of the target tense. The frequency of tense substitutes in the DLD group was almost as twice as that of the TD group (see Table 4). The tense substitutes were either finite forms or non-finite/tenseless forms. Finite substitutes involved the use of the incorrect tense (e.g., past tense for present tense). The non-finite substitutes involved the use of the imperfective bare verb and the imperative in place of the target tense.

The imperfective bare verb was most commonly used as a substitute for present tense by the DLD group, followed by the imperative and incorrect tense (e.g., past for present). Similarly, the most common present tense substitute in the TD group was the use of imperfective followed by the imperative and incorrect tense. The frequency of present tense substitutes significantly differed between groups $\left(\chi^{2}(2, N=201)=7.05, p<.05\right)$.

The DLD group used the imperative and the present tense as substitutes for past tense verbs.

562 of present tense. The TD group rarely used the imperative as a default form in place of past

563 tense. The frequency of past tense substitutes significantly differed between the TD and DLD groups $(\chi 2(2, N=54)=10.56, p<.001)$. 


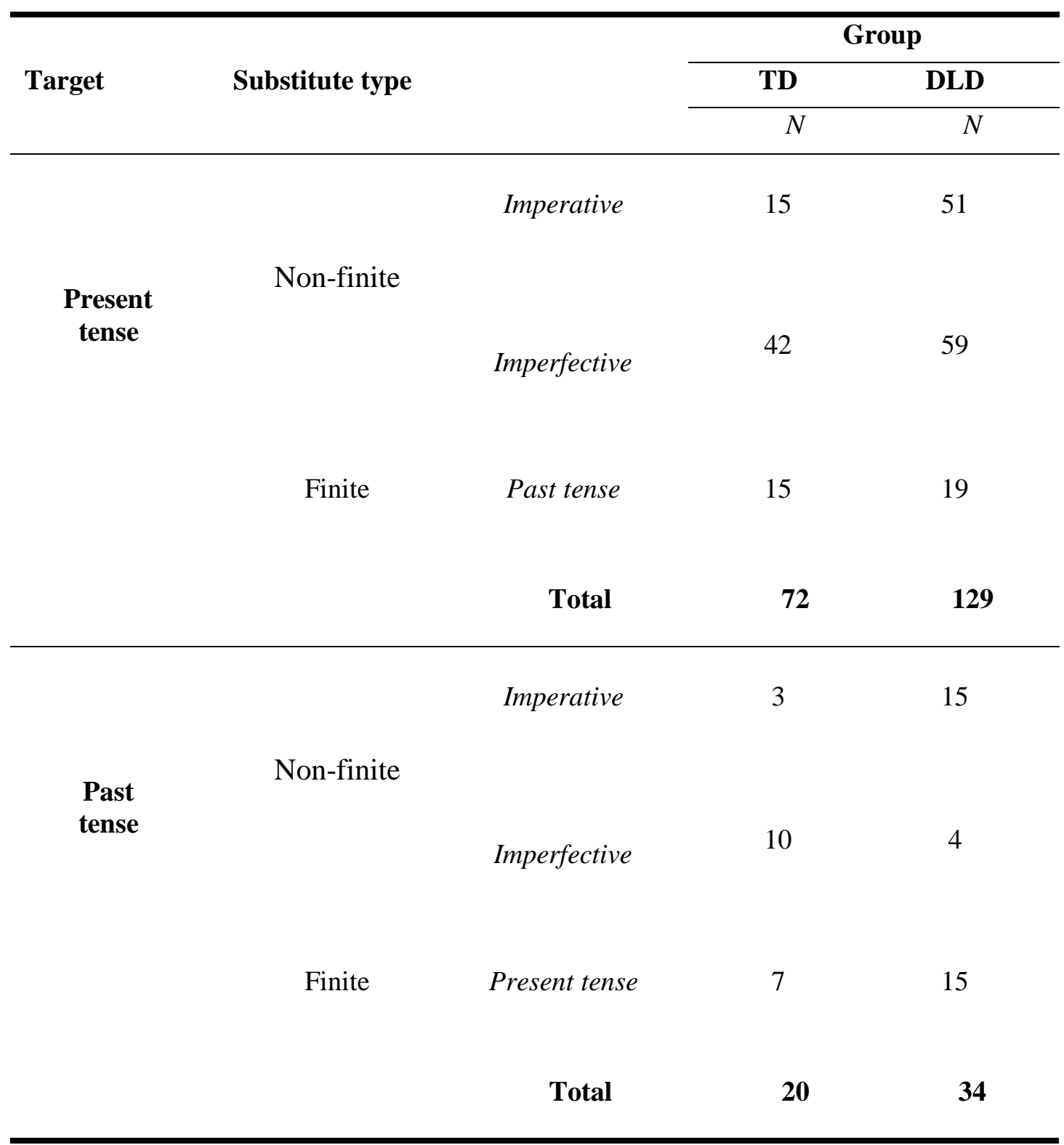

Note. $\mathbf{T D}=$ Typically Developing. $\mathbf{D L D}=$ Developmental Language Disorder.

571 Subject-verb agreement

572 For present tense verbs, the frequency of agreement errors in the DLD group was four times

573 that of the TD group (see Table 5). Inspection of the data in Table 5 reveals that some of the

574 agreement errors were associated with tense errors. The majority of the agreement errors were

575 related to the use of the imperative verb and affected person agreement only. The omission of 
the prefix byi- often resulted in the 3rd person present tense verb being substituted by the 2 nd

577 person imperative verb (tense and person errors). This type of error barely occurred in the TD

578 group. There were few instances where gender and/or number were also affected. An example

579 of this was the use of the 2nd person masculine imperative instead of 3rd person feminine

580 present tense (tense, person and gender errors).

581 There were also agreement errors that occurred despite using the correct tense. The majority

582 of errors in the TD and DLD groups affected the 3rd person plural present tense. Correct

583 agreement for this form requires the use of the circumfix (e.g. byi $-u$ in byidrusu "they are

584 studying”). In both groups, it was noted that the plural morpheme - $u$ was omitted which resulted

585 in the 3rd person singular verb (number agreement error). The 3rd person feminine singular

586 present tense form had the second-highest rate of errors in both groups. In both groups, this

587 form was substituted by its masculine counterpart (gender agreement error).

588 In general, the frequency of errors that affected past tense production was lower than present 589 tense production. As seen in Table 6, some of the agreement errors in past tense were associated

590 with tense errors. The majority of these errors were associated with the imperative and only

591 affected person agreement. For instance, when the 3rd person plural past tense was replaced with the 2nd person plural imperative (person and tense error). In a few occurrences, gender agreement was also affected. An example of this was the use of the 2nd masculine imperative

594 in place of third person feminine past tense (tense, person and gender errors).

595 When past tense was used correctly, the majority of agreement errors affected 3rd person 596 plural past tense. Both the TD and DLD group showed omissions of the plural suffix $-u$ which resulted in the 3rd person singular past tense as a substitute (number error). The 3rd person

598 feminine past tense had the second-highest number of errors in both groups. The omission of 599 the feminine suffix - at resulted in the 3rd person masculine as a substitute (gender error). 
Table 5. Frequency of Subject-verb agreement errors in present tense verbs

\begin{tabular}{|c|c|c|c|c|c|c|c|}
\hline \multirow[b]{3}{*}{ Actual productions } & & \multirow{2}{*}{\multicolumn{3}{|c|}{$\begin{array}{c}\text { TD } \\
\text { Target forms }\end{array}$}} & \multirow{2}{*}{\multicolumn{3}{|c|}{$\begin{array}{c}\text { DLD } \\
\text { Target forms }\end{array}$}} \\
\hline & & & & & & & \\
\hline & & $\begin{array}{c}\text { PRES-3MS } \\
\boldsymbol{b} \text {-yi-drus }\end{array}$ & $\begin{array}{c}\text { PRES-3FS } \\
\boldsymbol{b} \text { - } \boldsymbol{t} \text { - } d r u s\end{array}$ & $\begin{array}{c}\text { PRES-3P } \\
\boldsymbol{b} \text {-yi-drusu }\end{array}$ & $\begin{array}{c}\text { PRES-3MS } \\
\boldsymbol{b} \text {-yi-drus }\end{array}$ & $\begin{array}{c}\text { PRES-3FS } \\
\boldsymbol{b} \text {-ti-drus }\end{array}$ & $\begin{array}{c}\text { PRES-3P } \\
\boldsymbol{b} \text {-yi-drus-u}\end{array}$ \\
\hline \multirow{4}{*}{ Non-finite forms } & $\begin{array}{l}\text { IMPR-2FS } \\
\text { Pidrusi }\end{array}$ & & 3 & & & 8 & 2 \\
\hline & $\begin{array}{l}\text { IMPR-2MS } \\
\text { Pidrus }\end{array}$ & 4 & 2 & 6 & 15 & 2 & 2 \\
\hline & $\begin{array}{l}\text { IMPR-2P } \\
\text { pi-drus-u }\end{array}$ & & & & & & 23 \\
\hline & $\begin{array}{c}\text { IMPF-3MS } \\
y \boldsymbol{y}-d r u s\end{array}$ & & & & & 1 & \\
\hline \multirow{4}{*}{ Incorrect tense } & $\begin{array}{c}\text { IMPF-3FS } \\
\text { ti-drus }\end{array}$ & & & & 3 & & \\
\hline & $\begin{array}{c}\text { IMPF-3P } \\
\text { ti-drusu }\end{array}$ & & & & & 1 & \\
\hline & $\begin{array}{l}\text { PAST-3MS } \\
\text { daras }\end{array}$ & & & 1 & & 3 & 1 \\
\hline & $\begin{array}{c}\text { PAST-3FS } \\
\text { dars-at }\end{array}$ & & & & & & 1 \\
\hline \multirow[t]{2}{*}{ Correct tense } & $\begin{array}{c}\text { PRES-3MS } \\
\boldsymbol{b}-\boldsymbol{y i} \boldsymbol{i}-d r u s\end{array}$ & & 1 & 5 & & 5 & 13 \\
\hline & $\begin{array}{c}\text { PRES-3FS } \\
\boldsymbol{b} \text {-ti-drus }\end{array}$ & & & 3 & & & 0 \\
\hline Total & & 4 & 6 & 15 & 18 & 20 & 42 \\
\hline
\end{tabular}

Note. TD $=$ Typically Developing. DLD = Developmental Language Disorder. PRES-3MS = present 3rd person masculine singular. PRES-3FS $=$ present 3 rd person feminine singular. PRES-3P $=$ present 3 rd person plural. IMPR-2FS $=$ Imperative $2^{\text {nd }}$ person feminine singular. IMPR-2MS $=$ Imperative $2^{\text {nd }}$ person masculine singular. IMPR-2P $=$ Imperative $2^{\text {nd }}$ person plural. IMPF-3MS $=$ imperfective $3^{\text {rd }}$ person masculine singular. IMPF-3FS $=$ imperfective $3^{\text {rd }}$ person feminine singular. IMPF-3P $=$ imperfective $3^{\text {rd }}$ person plural. PAST-3MS $=$ past $3^{\text {rd }}$ person masculine singular. PAST-3FS $=$ past $3^{\text {rd }}$ person feminine singular. 
Table 6. Frequency of Subject-verb agreement errors in past tense verbs

\begin{tabular}{|c|c|c|c|c|c|c|c|}
\hline \multirow[b]{2}{*}{ Actual productions } & & \multicolumn{3}{|c|}{$\begin{array}{c}\text { TD } \\
\text { Target forms }\end{array}$} & \multicolumn{3}{|c|}{$\begin{array}{c}\text { DLD } \\
\text { Target forms }\end{array}$} \\
\hline & & $\begin{array}{l}\text { PAST-3MS } \\
\quad \text { daras }\end{array}$ & $\begin{array}{c}\text { PAST-3FS } \\
\text { dars-at }\end{array}$ & $\begin{array}{l}\text { PAST-3P } \\
\text { daras- } \boldsymbol{u}\end{array}$ & $\begin{array}{c}\text { PAST-3MS } \\
\text { daras }\end{array}$ & $\begin{array}{c}\text { PAST-3FS } \\
\text { dars-at }\end{array}$ & $\begin{array}{r}\text { PAST-3P } \\
\text { daras-u }\end{array}$ \\
\hline \multirow{4}{*}{ Non-finite forms } & $\begin{array}{c}\text { IMPR-2MS } \\
\text { pi-drus }\end{array}$ & 2 & 3 & & 3 & 2 & \\
\hline & $\begin{array}{c}\text { IMPR-2FS } \\
\text { pi-drus-i }\end{array}$ & & 1 & & & 4 & \\
\hline & $\begin{array}{l}\text { IMPR-2P } \\
\text { P-idrus-u }\end{array}$ & & & 1 & & & 5 \\
\hline & $\begin{array}{c}\text { IMPF-3MS } \\
y \boldsymbol{i}-d r u s\end{array}$ & & & & & 1 & \\
\hline Incorrect tense & $\begin{array}{l}\text { PRES-3MS } \\
\boldsymbol{b} \text {-yi-drus }\end{array}$ & & 1 & & & 1 & 2 \\
\hline \multirow{3}{*}{ Correct tense } & $\begin{array}{c}\text { PAST-3MS } \\
\text { daras }\end{array}$ & & 2 & 12 & & 5 & 8 \\
\hline & $\begin{array}{c}\text { PAST-3FS } \\
\text { dars-at }\end{array}$ & & & 3 & 1 & & 5 \\
\hline & $\begin{array}{c}\text { PAST-3P } \\
\text { daras-u }\end{array}$ & & & & 1 & & \\
\hline Total & & 2 & 7 & 16 & 5 & 13 & 20 \\
\hline
\end{tabular}

Note. TD $=$ Typically Developing. DLD $=$ Developmental Language Disorder. PAST-3MS $=$ past 3rd person masculine singular. PAST-3FS $=$ past 3rd person feminine singular. PAST-3P $=$ past 3 rd person plural. IMPR-2MS $=$ Imperative $2^{\text {nd }}$ person masculine singular. IMPR-2FS $=$ Imperative $2^{\text {nd }}$ person feminine singular. IMPR-2P $=$ Imperative $2^{\text {nd }}$ person plural. IMPF-3MS $=$ imperfective $3^{\text {rd }}$ person masculine singular. IMPF-3FS $=$ imperfective $3^{\text {rd }}$ person feminine singular. 


\section{Discussion}

606 This study examined verb morphology production in Palestinian Arabic-speaking children

607 with Developmental Language Disorder (DLD) and their typically developing peers (TD).

608 Using a novel verb production task, we aimed to compare children with and without DLD in

609 terms of their (1) accuracy rates and (2) error patterns of marking tense and subject-verb

610 agreement.

\section{The production accuracy of verb tense and agreement marking}

612 As predicted, there was a significant difference between children with and without DLD in

613 the percentage of correct use of tense and subject-verb agreement verb inflections, with the

614 DLD group scoring significantly lower than the TD group on the verb elicitation task. This suggests that PA-speaking children with DLD have difficulties in using verbal tense and agreement forms. These findings corroborate the well-documented evidence that verb morphology production is an area of vulnerability for children with DLD acquiring Arabic

618 (Abdallah \& Crago, 2008; Morsi, 2009; Fahim, 2017), just as it is for other languages, such as

619 English (e.g., Rice \& Wexler, 1996), German (e.g., Rothweiler, Chilla \& Clahsen, 2012);

620 Swedish (e.g., Hansson \& Leonard, 2003), Hebrew (e.g., Leonard\& Dromi, 1994) and Italian 621 (e.g., Bortolini et al., 1997).

622 Overall, the percentage of correct tense marking in the DLD group (82\%) was significantly 623 lower than in the TD group. When the accuracy scores of the groups for both tense forms were 624 contrasted, a remarkable pattern emerged. Despite significant group differences, TD children and children with DLD produced past tense verbs with a high level of accuracy, scoring $98 \%$ and $92 \%$, respectively. Conversely, the DLD group had significant difficulties with their use

627 of present tense, with a mean accuracy of $70 \%$. The specific difficulty with present tense 628 production was reported previously for Arabic-speaking children with DLD (e.g., Abdallah 629 and Crago, 2008; Morsi, 2009) and it is unlike other languages where a considerable body of 
research has reported greater difficulties with the past tense, as in English (e.g., Rice \& Wexler,

631 1996). A possible factor for differences in which tense forms are affected in different languages

632 is structural complexity. For example, a higher number of errors exhibited by Hebrew-speaking

633 children with DLD in using past tense relative to present tense has been attributed to the higher

634 number of agreement features required for the past inflection (Dromi et al., 1999). Following

635 this view, in PA, the past tense form is less marked, structurally simpler than the present tense

636 (as discussed in the Introduction). For example, the verb daras "he studied", is formed by

637 combining the vocalic pattern $a-a$ with the root $d-r-s$ ( there is no overt marking of tense),

638 whereas the present form byidrus "he is studying" entails the insertion of a vocalic pattern - $u$ -

639 plus the addition of a prefix byi-, where the politic $b$-indicates present tense.

640 In terms of subject-verb agreement, children with DLD produced $85 \%$ of the verbs with the

641 correct agreement for all categories, and this was significantly lower than the TD group who

642 showed an almost ceiling effect, with their agreement accuracy being 97\%. Interestingly, the

643 overall accuracy for marking agreement in the DLD group was higher than for marking tense.

644 This suggests that marking of tense was more problematic than marking subject-verb

645 agreement for our sample. Abdallah and Crago (2008) who also reported that preschool-age,

646 Hijazi Arabic-speaking children had higher accuracy scores in marking subject-verb agreement

$647(77 \%)$ compared to tense $(68 \%)$.

648 Difficulty with subject-verb agreement is not surprising as the subject and verb must agree

649 on several grammatical categories including person, number and gender. Furthermore, 650 agreement in PA in fusional, where more than one agreement category is denoted by a single 651 inflection. For example, the suffix $-a t$ in darsat "she studied" denotes $3^{\text {rd }}$ person, feminine 652 gender and singular number simultaneously. In other instance, agreement categories denoted 653 by a circumfix affix, where a prefix and suffix are required. An example of this is the circumfix 654 byi $-u$ in byidrusu where it indicates $3^{\text {rd }}$ person plural agreement (no gender distinction). 
655 Having to express more than one agreement category simultaneously using less transparent

656

657

658

659

660

661

662

663

664

665

666

667

668

669

670

671

672

673

674

675

676

677

678

679 morphemes could be contributing factors in making these forms more challenging (Dromi et al., 1999).

Examination of gender agreement marking revealed that the DLD group was similar to the TD group in producing masculine verb forms but were less accurate in producing feminine verb forms. Several factors could explain the greater difficulty with marking feminine agreement observed in the DLD group. This pattern was also found in Hijazi- Arabic speaking children with DLD (Abdallah \& Crago, 2008). First, in the typical acquisition of Arabic, masculine verb forms are acquired earlier than feminine verb forms, both in production (Aljenaie, 2000) and comprehension (Al-Akeel, 1998). Furthermore, masculine verb forms are less marked compared to feminine forms (e.g., daras "he studied" versus darsat "she studied").

Looking at number agreement marking, the DLD group was similar to the TD group in producing singular and plural verbs. However, the DLD group was less accurate in their use of plural verbs compared to singular verbs. This can be attributed to the order in which these forms appear in typical development. Singular verb forms are acquired earlier than plural verb forms, both in production (Abdu \& Abdu, 1986; Aljenaie, 2001; Basaffar \& Safi, 2012; Omar, 1973) and comprehension (Al-Akeel, 1998; Moawad, 2006). Moreover, singular number agreement is unmarked any overt inflections in present and past tense verbs whereas plural number agreement is by the suffix - $u$ (e.g., daras "he studied" versus darasu " they studied"). In regards to person agreement, though there were significant differences between the TD and DLD groups, both groups marked $3^{\text {rd }}$ person agreement with more than $90 \%$ of accuracy. This high level of accuracy can be attributed to the fact that $3^{\text {rd }}$ person verbs are the first to emerge in the language of TD children acquiring Arabic (Abdu \& Abdu, 1986; Aljenaie, 2001; Basaffar \& Safi, 2012). Our findings are in contrast to the findings of Abdallah and Crago (2008) who reported that Hijazi-Arabic speaking children with DLD had a difficulty with 
person agreement as they produced $3^{\text {rd }}$ person verbs with $66 \%$ of accuracy (compared to $92 \%$

681 in our study). This difference can be attributed to age differences: in our study the mean age of 682 the DLD group was 66 months with the oldest child being 94 months) whereas in Abdallah and 683 Crago (2008)'s study, the mean age of the DLD group was 57 months with the oldest child 684 being 63 months).

685 An interesting observation emerged regarding stressed and unstressed affixes ( for a 686 description of stress patterns in PA, see Watson, 2011). Despite the lack of significant statistical differences, the DLD group produced present tense verbs with the stressed prefix more accurately than verbs with the unstressed prefix. Looking specifically at the present tense

689 feminine inflection bti- and its allomorph bit-, the DLD group used present tense feminine 690 verbs with a stressed prefix with $79 \%$ of accuracy compared to $61 \%$ of accuracy for verbs with an unstressed prefix. This discrepancy could possibly be attributed to the lower acoustic salience unstressed prefixes.

Furthermore, the past tense feminine agreement morpheme -at as in 'dar.sat "she studied" was challenging for the DLD group in our study. This inflection occurs at the end of the word as part of an unstressed syllable, making the suffix -at more likely to be missed by children with DLD possibly due to its lower acoustic salience. This suffix was often omitted from the past feminine verb forms resulting in a masculine verb da.ras "he studied". The plural inflection $-u$ as in 'da.ra.su "they studied" was not problematic for the DLD group. The plural inflection always occurs in a final unstressed syllable (Watson, 2011), which would have lower

700 acoustic salience relative to the other syllables in the verb. Stressed syllables are typically louder and longer making them have a high perceptual salience. Although the accuracy of using inflections was higher when they were stressed compared to being unstressed, the scores of the DLD group on the stressed inflections were relatively low. This suggests that, even though children with DLD may have difficulties in perceiving morphemes of low acoustic saliency, 
705

706

707

708

709

710

711

712

713

714

715

716

717

718

719

720

721

722

723

724

725

726

727

728

729

this is unlikely to be the only factor that underpins their difficulties with verb morphology production and further research is needed to address this issue.

\section{Error patterns in verb morphology production}

Qualitative analysis revealed that the target tense forms were substituted by either finite forms (incorrect tense) or non-finite/tenseless forms (imperative and the imperfective bare verb). Interestingly, the TD and DLD groups appear to display the same tense substitution patterns, but they differ in the frequency of their use. As predicted, the most frequent tense substitution patterns in the DLD group were the use of the imperative as well the imperfective bare verb. These two non-finite forms occurred with equal frequency. On the other hand, the use of the imperfective bare was the most common substitute noted in the TD group, whereas the imperative was used less frequently in this group. The use of incorrect tense (e.g., past for present tense) was the least occurring tense error in both groups.

A considerable body of research has shown that the verb morphology error patterns displayed by children with DLD are similar to those observed in younger TD children acquiring the same language (Leonard, 2014). In fact, according to the Extended Optional Infinitive (EOI; e.g., Rice \& Wexler, 1996; Rice, Wexler, \& Cleave, 1995), children with and without DLD go through an $O I$ stage in which they treat marking of tense and agreement as being optional in obligatory contexts (e.g., Rice \& Wexler, 1996). For example, English and German-speaking children with DLD tend to use infinitives or bare stem forms instead of the target tense (Rice \& Wexler, 1996). Arabic has no infinitive forms. Yet, a stage similar to OI seems to exist in this language. Children with and without DLD in our study used the imperative and imperfective bare verb forms instead of target tense. The use of the imperative has been observed in the language of TD toddlers acquiring Yemini Arabic (Qasem \& Sircar, 2017), Egyptian Arabic (Fahim, 2017; Omar, 1973) and Kuwaiti Arabic (Aljenaie, 2001) as well as children with DLD acquiring Hijazi Arabic (Abdallah \& Crago, 2008) and Egyptian Arabic 
730 (Fahim, 2017; Morsi, 2009). The imperfective bare stem has been observed in the language of

731 TD children acquiring Kuwaiti Arabic (Aljenaie, 2010) and children with and without DLD 732 acquiring Egyptian Arabic (Fahim, 2017). In accordance with EOI, the use of the imperative 733 and the imperfective bare verb forms as default forms is extended for a longer period in Arabic734 speaking children with DLD. Both of these forms are described as being non-finite (Ajlenaie, 735 2010) or tenseless (Benmamoun 1999, 2000). Children with and without DLD in our study also used finite forms instead of the target. Our findings thus emphasize that the typology of a language impacts both on the type of structures affected by DLD and on the type of errors that characterize the disorder. Our findings also expand on Paradis and Crago's (2004) proposal that the term "default form" refers to the optional use of either non-finite or finite forms instead of target tense, which is observed in children with and without DLD.

A closer look at the types of errors in subject-verb agreement reveals an interesting pattern.

The of the masculine verb instead of the feminine verb was the most dominant gender agreement error in the DLD and TD groups. The error involved the omission of the suffix -at of past tense feminine verbs, or the prefix bti- /bit- of present tense feminine verbs. This type of error has been reported to Arabic-speaking children with typical language development (Aljenaie, 2001, 2010; Omar, 1973) and with DLD (Abdallah, 2002; Abdallah \& Crago, 2008;

747 Fahim, 2005).

For the TD and DLD groups, the most dominant number agreement error was the omission of the plural suffix $-u$ of the past tense, or the suffix $-u$ of the circumfix $b y i-u$ in the present

750 tense verb. This pattern was observed in the TD and DLD groups. This omission error resulted in the unmarked singular verb being a substitute of the marked plural verb. The use of singular verbs in placed of plural verbs has also been documented in Arabic speaking children with and without DLD (Abdallah, 2002; Abdallah \& Crago, 2008; Aljenaie, 2001, 2010; Omar, 1973).

754 It can be seen that, in line with our prediction, gender and number agreement errors involved 
the use of the unmarked form instead of the marked form. In this case, the unmarked masculine and singular verbs were used instead of the marked feminine and plural verbs, respectively. This pattern has been also reported for Kuwaiti Arabic-speaking TD children (Aljenaie, 2001, 2010) and Hijazi Arabic-speaking children with DLD (Abdallah \& Crago, 2008). These findings are in support of Omar (1973)'s suggestion that the third masculine singular may be the default verbal agreement form in Arabic.

We only examined the subject-verb agreement for $3^{\text {rd }}$ person verbs. Person agreement errors were primarily associated with tense errors. This occurred in cases where the imperative was used instead of the target tense. This pattern differs from the findings of Abdallah \& Crago (2008) who documented that Hijazi Arabic-speaking children with DLD used $1^{\text {st }}$ person verbs in place of 3rd person verbs. The pattern also differs from studies reporting that the 3 rd person verbs emerge earlier than $2^{\text {nd }}$ person verbs (Abdu \& Abdu, 1986; Aljenaie, 2001, 2010; Basaffar \& Safi, 2012). In the DLD group, the imperative was mostly used instead of present tense verbs $(N=51)$ and much less frequently in place of past tense verbs $(N=15)$. Third person agreement is realized by the prefix of the present tense verb or the suffix of the past tense verb, whereas, the impertive $2^{\text {nd }}$ person agreement is unmarked by any affixes. Therefore, it appears person agreement errors represent the use of the unmarked $2^{\text {nd }}$ person imperative instead of the marked $3^{\text {rd }}$ person present/past tense verb. Based on the current data and the test items, it is difficult to determine whether the difficulty is in marking tense or person agreement. To determine this, an additional examination of $1^{\text {st }}$ and $2^{\text {nd }}$ person verb production is needed. It is important to not that Abdallah and Crago (2008) reported that when Hijazi Arabicspeaking children with and without DLD made tense or agreement errors, the inaccurate production differed from the target verb by one feature only. Inspection of our data reveals a similar pattern. Apart from the use of the imperative ( tense and person error), the majority of errant productions of the TD and DLD groups differed from the target by one feature. These 
errors are referred to as being "near misses" and have been documented in richly inflected

781 languages such as Hebrew and Spanish ( for a review, see Leonard, 2014). Another important

782 observation is that most errors in the TD and DLD groups were made in forms in which 783 agreement is realized by a circumfix morpheme. In our study, this form was the $3^{\text {rd }}$ plural

784 present tense verb in which tense, person and number agreement are expressed by the circumfix 785 byi-- $u$. The children in our study treated the circumfix affixes as separate units. The most common error was the omission of the prefix byi- while retaining the suffix $-u$. A similar pattern was noted in Kuwaiti Arabic in which the $3^{\text {rd }}$ plural present tense verb is expressed with the circumfix yi--oon. Aljenaie (2001) found that the TD Kuwaiti Arabic-speaking children tended to omit the prefix $y i$ - and maintain the suffix -oon. The second error pattern in our study

790 involved omission of the plural suffix $-u$ while retaining the prefix, and this pattern was documented in Hijazi Arabic-speaking children with DLD (Abdallah \& Crago, 2008) and was also observed in TD Kuwaiti Arabic-speaking children (Aljenaie, 2010).

793

795

796

797

798

799

800

801

802

\section{Clinical implications}

Given the lack of standardized Arabic assessments for PA, the diagnosis of DLD is based on informal evaluation procedures that are combined with subjective clinical judgments, which may lead to variations and inconsistences across speech and language therapists (SLTs) as to which structures are targeted in the assessment of DLD. The results of our study provide SLTs with a description of specific verb morphology difficulties in Arabic-speaking children with DLD. Significant differences between children with DLD and TD controls were found in using present tense and verbs with feminine inflections. The findings indicate that SLTs should consider targeting these structures in the assessment and intervention of PA children with DLD.

\section{Limitations}

One of the limitations was the small sample size of the DLD group. This is due to the limited number of clinics in [REMOVED FOR REVIEW] from which this group was recruited. Future 
studies are recommended to include larger sample sizes. The study provides results about the deficits of verb morphology production only and no data on children's comprehension of verb morphology. To achieve a full understanding of the underlying mechanisms of DLD, other aspects of verb morphology should be examined. These should include comprehension and grammaticality judgment tasks, tasks investigating 1st and 2nd person morphemes and tasks

810 which target derivational as well as inflectional morphology.

\section{Conclusion}

812 The findings show that Palestinian Arabic-speaking children with DLD present with deficits

813 in the production of verb morphology relative to typically developing children. Inflected verbs

814 with increased markedness including present tense and feminine verb form were more 815 challenging for the DLD group than past tense, masculine verb forms, respectively. For the TD 816 and DLD groups, the most frequent tense and agreement error patterns included omissions of 817 the target morphemes. The omission of target morphemes often resulted in the children 818 producing structurally simpler (less marked) verb forms instead of marked verb forms. And 819 although it seemed that the DLD group was more accurate with some stressed than unstressed 820 forms, the scores of the DLD group were still lower than the TD group. Future studies would 821 need to include larger sample sizes to increase statistical power and generalizability of the 822 findings, investigate other aspects of verb morphology, including both production and 823 comprehension consider other language domains, such as syntax, phonology and semantics 824 and employ longitudinal designs to provide more in-depth knowledge of Arabic language 825 acquisition.

\section{Acknowledgments}

827 We would like to thank the children and their parents who participated in the study. We also 828 thank the teachers and speech and language therapists who facilitated recruitment of the 
830 with DLD.

831

832 


\section{References}

834 Abdallah, F. (2002). Specific Language Impairment in Arabic-speaking children: Deficits in Morphosyntax. (Unpublished Thesis). McGill University.

Abdallah, F., \& Crago, M. (2008). Verb morphology deficits in Arabic-speaking children with specific language impairment. Applied Psycholinguistics, 29(2), 315-340.

838

Abdu, D., \& Abdu, S. (1986). Dirasa fi mufradat tiflayn. Dhaat al-Salaasil Publication.

Abi-Aad, K., \& Atallah, C. (2012). Phonologie, Plurilinguisme et Trouble Spécifique du Langage Oral au Liban : Etude Pilote sur la Pertinence d' 'un Test de Répétition de NonMots. (Unpublished Thesis). Universite Saint-Joseph.

Abu-Ghazaleh, I. N. (1983). Theme and the function of the verb in Palestinian Arabic narrative discourse. (Unpublished Thesis). University of Florida.

Al-Akeel, A. (1998). The acquisition of Arabic language comprehension by Saudi children. (Unpublished Thesis). Newcastle University.

Al-Aqarbeh. (2011). Finiteness in Jordanian Arabic: a semantic and morphosyntactic approach. (Unpublished Thesis). The University of Kansas.

Aljenaie, K. (2000). The emergence of tense and agreement in Kuwaiti children speaking Arabic. Reading Working Papers in Linguistics, 4(1), 1-24.

Aljenaie, K. (2001). The emergence of tense and agreement in Kuwaiti Arabic children. (Unpublished Thesis). In Linguistics and Applied Studies. The University of Reading.

852 Aljenaie, K. (2010). Verbal inflection in the acquisition of Kuwaiti Arabic. Journal of Child Language, 37(4), 841-863.

Basaffar, F., \& Safi, S. (2012). The acquisition of verb inflections in Hijazi Arabic. Arab World English Journal, 3, 266-304.

856 Bedore, L. M., \& Leonard, L. B. (1998). Specific Language Impairment and Grammatical Morphology. Journal of Speech, Language, and Hearing Research, 41(5), 1185-1192. 
Bedore, L. M., \& Leonard, L. B. (2001). Grammatical Morphology Deficits in SpanishSpeaking Children With Specific Language Impairment. Journal of Speech, Language, and Hearing Research, 44(4), 905-924.

Benmamoun, E. (1999). Arabic morphology: The central role of the imperfective. Lingua, $108(2-3), 175-201$.

Benmamoun, E. (2000). The Tense Systems of Egyptian Arabic, Moroccan Arabic, and Standard Arabic. In The feature structure of functional categories: A comparative study of Arabic dialects (pp. 19-36). Oxford University Press.

Bortolini, U., Caselli, M. C., \& Leonard, L. B. (1997). Grammatical Deficits in ItalianSpeaking Children With Specific Language Impairment. Journal of Speech, Language, and Hearing Research, 40(4), 809-820.

Conti-Ramsden, G., Botting, N., \& Faragher, B. (2001). Psycholinguistic markers for specific 870 language impairment (SLI). Journal of Child Psychology and Psychiatry and Allied Disciplines, 42(6), 741-748.

873

Corbett, G. G. (1991). Gender. Cambridge University Press.

Corbett, G. G. (2000). Number. Cambridge University Press.

Dromi, E., \& Berman, R. A. (1982). A morphemic measure of early language development: Data from modern Hebrew. Journal of Child Language, 9(2), 403-424.

Dromi, E., Leonard, L. B., Adam, G., \& Zadunaisky-Ehrlich, S. (1999). Verb Agreement Morphology in Hebrew-Speaking Children With Specific Language Impairment. Journal of Speech, Language, and Hearing Research, 42(6), 1414-1431.

Fahim, D. (2005). Developmental Language Impairment in Egyptian Arabic.(Unpublished Thesis). Birkbeck, University of London.

881 Fahim, D. (2017). Verb Morphology in Egyptian Arabic Developmental Language 882 Impairment. Arab Journal of Applied Linguistics, 2(1), 49-73. 
Field, A. (2009). Discovering Statistics using IBM SPSS Statistics (Third edit). SAGE Publications Ltd.

885

886

887

888

889

890

891

892

893

894

895

896

897

898

899

900

901

902

903

904

905

906

907

Haeri, N. (2000). Form and Ideology : Arabic Sociolinguistics and Beyond. Annual Review of Anthropology, 29(1), 61-87.

Hansson, K., \& Leonard, L. B. (2003). The use and productivity of verb morphology in specific language impairment: an examination of Swedish. Journal of Speech, Language, and Hearing Research, 44(384), 351-379.

Jarrar, M., Habash, N., Akra, D., \& Zalmout, N. (2014). Building a Corpus for Palestinian Arabic: a Preliminary Study. Proceedings Ofthe EMNLP 2014 Workshop on Arabic Natural Langauge Processing (ANLP), 18-27.

Krok, W. C., \& Leonard, L. B. (2015). Past Tense Production in Children With and Without Specific Language Impairment Across Germanic Languages: A Meta-Analysis. Journal of Speech, Language, and Hearing Research, 58, 1326-1340.

Leech, G. (2006). A Glossary of English Grammar. Edinburgh University Press.

Leonard, L. B. (2014). Children with specific language impairment (2nd ed.). MIT Press.

Leonard, L. B., \& Dromi, E. (1994). The use of Hebrew verb morphology by children with specific language impairment and children developing language normally. First Language, 14(42-43), 283-304.

Leonard, L. B., \& Kueser, J. B. (2019). Five overarching factors central to grammatical learning and treatment in children with developmental language disorder. International Journal of Language and Communication Disorders, 54(3), 347-361.

Mayer, M. (1969). Frog, where are you? Dial books for Young Readers.

McCarthy, J. J., \& Prince, A. (1988). -Quantitative Transfer in Reduplicative Templatic Morphology and John McCarthy and Alan Prince. Linguistics in the Morning Calm, 2(99).

Moawad, R. A. (2006). The acquisition of the Arabic gender and number systems. 

(Unpublished Thesis). University of Wales.

909

910

911

912

913

914

915

916

917

918

919

920

921

922

923

924

925

926

927

928

929

930

931

932

Morsi, R. (2009). Specific Language Impairment in Egyptian Arabic: A preliminary investingation. (Unpublished Thesis). University of Reading.

Omar, M. (1973). The acquisition of Egyptian Arabic as a native language (Janua ling). Mouton \& Co N.V.

Ouali, H. (2018). The Syntax of Tense in Arabic. In Elabbas Benmamoun \& R. Bassiouney (Eds.), The Routledge Handbook of Arabic Linguistics (pp. 89-103). Routledge.

Paradis, J., \& Crago, M. (2004). The Morphosyntax of Specific Language Impairment in French: An Extended Optional Default Account. Language Acquisition, 9(4), 269-300.

Qasem, F., \& Sircar, S. (2017). Imperative as root infinitive analogue in Yemeni Ibbi Arabic: Two case studies. Arab Journal of Applied Linguistics, 2(1), 2490-4198.

Rice, M L, \& Wexler, K. (1996). Toward tense as a clinical marker of specific language impairment in English-speaking children. Journal of Speech, Language, and Hearing Research, 39(6), 1239-1257.

Rice, Mabel L., Wexler, K., \& Cleave, P. L. (1995). Specific Language Impairment as a Period of Extended Optional Infinitive. Journal of Speech, Language, and Hearing Research, $38(4), 850-863$

Rothweiler, M., Chilla, S., \& Clahsen, H. (2012). Subject-verb agreement in Specific Language Impairment: A study of monolingual and bilingual German-speaking children. Bilingualism, 15(1), 39-57.

RStudioTeam. (2019). RStudio: Integrated Development for R. RStudio, Inc.

Ryding, K. (2005). Verb inflection: a summary. A reference grammar of modern standard Arabic (First Edit, pp. 438-446). Cambridge university press.

Shaalan, S. (2010). Investigating Grammatical Complexity in Gulf Arabic Speaking Children with Specific Language Impairment (SLI). (Unpublished Thesis). University College 

London.

934 Shaalan, Saleh, \& Khater, M. (2006). A comparison of two measures of assessing spontaneous language samples in Arabic speaking children.

936 Shahin, K. (2010). Fostering language development in Arabic. In Encyclopedia of language and literacy development (pp. 1-9). Canadian Language and Literacy Research Network.

Shahin, Kimary. (2007). Palestinian Arabic. In M. Eid, A. Elgibali, K. Versteegh, M. Woldich, $538)$

Soltan, U. (2007). On agree and postcyclic merge in syntactic derivations: First conjunct agreement in standard Arabic. Perspectives on Arabic Linguistics, 19, 191-213.

Taha, J., \& Chondrogianni, V. (2017). Nonword repetition as a risk marker in Palestinian children with and without delayed language development. (Unpublished dissertation). The University of Edinburgh.

Tucker, M. A. (2011). The morphosyntax of the Arabic verb: Toward a unified syntax-prosody. In N. LaCara, A. Thompson, \& M. A. Tucker (Eds.), Morphology at Santa Cruz: Papers in Honor of Jorge Hankamer (pp. 177-211). Linguistics Research Center.

Watson, J. C. E. (2011). Word Stress in Arabic. In M. van Oostendorp, C. Ewen, E. Hume, \& 
962 Individual raw scores of the background measures and the verb elicitation task for the TD and 963 DLD groups

964

\begin{tabular}{|c|c|c|c|c|c|c|}
\hline subject & gender & age & $M P U$ & $\begin{array}{c}C L-N W R \\
\text { (score out of 30) }\end{array}$ & $\begin{array}{c}C P M \\
\text { (score out of 36) }\end{array}$ & $\begin{array}{c}\% \text { of correct } \\
\text { verbs }\end{array}$ \\
\hline DLD1 & $\mathrm{M}$ & 67 & 2.88 & 17 & 20 & 55 \\
\hline DLD2 & M & 69 & 3.14 & 19 & 21 & 70 \\
\hline DLD3 & $\mathrm{F}$ & 84 & 4.06 & 16 & 23 & 60 \\
\hline DLD4 & $\mathrm{F}$ & 85 & 4.1 & 12 & 20 & 51 \\
\hline DLD5 & M & 52 & 3.21 & 13 & 12 & 90 \\
\hline DLD6 & M & 58 & 3.12 & 10 & 18 & 65 \\
\hline DLD7 & M & 50 & 2.62 & 11 & 11 & 68 \\
\hline DLD8 & M & 94 & 6.27 & 23 & 19 & 91 \\
\hline DLD9 & M & 54 & 3.22 & 16 & 12 & 88 \\
\hline DLD10 & M & 48 & 2.19 & 9 & 10 & 78 \\
\hline DLD11 & $\mathrm{F}$ & 56 & 3.21 & 16 & 12 & 86 \\
\hline DLD12 & M & 66 & 4.98 & 18 & 16 & 96 \\
\hline DLD13 & M & 61 & 3.36 & 21 & 9 & 100 \\
\hline DLD14 & $\mathrm{F}$ & 89 & 3.77 & 17 & 14 & 78 \\
\hline TD1 & M & 57 & 6.47 & 30 & 19 & 100 \\
\hline TD2 & M & 59 & 5.21 & 30 & 14 & 98 \\
\hline TD3 & M & 71 & 4.19 & 30 & 18 & 100 \\
\hline TD4 & $\mathrm{F}$ & 75 & 5.46 & 30 & 16 & 100 \\
\hline TD5 & $\mathrm{F}$ & 42 & 2.97 & 19 & 8 & 91 \\
\hline TD6 & $\mathrm{M}$ & 60 & 5.1 & 30 & 17 & 100 \\
\hline TD7 & F & 66 & 5.26 & 29 & 21 & 100 \\
\hline TD8 & $\mathrm{F}$ & 56 & 3.46 & 28 & 18 & 96 \\
\hline TD9 & $\mathrm{F}$ & 84 & 6.31 & 30 & 21 & 100 \\
\hline TD10 & $\mathrm{F}$ & 54 & 3.93 & 30 & 14 & 93 \\
\hline TD11 & $\mathrm{F}$ & 56 & 5.11 & 28 & 15 & 96 \\
\hline TD12 & $\mathrm{F}$ & 36 & 2.41 & 16 & NA & 65 \\
\hline TD13 & $\mathrm{M}$ & 83 & 5.89 & 30 & 22 & 100 \\
\hline TD14 & $\mathrm{F}$ & 54 & 4.9 & 27 & 17 & 98 \\
\hline TD15 & $\mathrm{M}$ & 48 & 3.93 & 24 & 15 & 96 \\
\hline TD16 & $\mathrm{M}$ & 85 & 6.01 & 30 & 21 & 100 \\
\hline TD17 & M & 80 & 5.68 & 30 & 15 & 100 \\
\hline TD18 & $\mathrm{M}$ & 79 & 5.13 & 30 & 19 & 98 \\
\hline TD19 & M & 68 & 4.88 & 29 & 19 & 98 \\
\hline TD20 & $\mathrm{F}$ & 51 & 3.79 & 27 & 14 & 98 \\
\hline TD21 & $\mathrm{M}$ & 65 & 3.92 & 25 & 21 & 98 \\
\hline TD22 & M & 96 & 7.61 & 30 & 23 & 100 \\
\hline TD23 & $\mathrm{M}$ & 87 & 6.58 & 30 & 20 & 100 \\
\hline
\end{tabular}




\begin{tabular}{lcccccc} 
TD24 & M & 41 & 2.83 & 19 & 9 & 80 \\
TD25 & M & 90 & 7.24 & 30 & 20 & 100 \\
TD26 & M & 73 & 5.96 & 30 & 18 & 100 \\
TD27 & F & 39 & 3.87 & 19 & NA \\
TD28 & F & 43 & 4.21 & 21 & 8 & 73 \\
TD29 & F & 47 & 4.53 & 25 & 10 & 80 \\
TD30 & M & 49 & 4.69 & 23 & 15 & 91 \\
TD31 & M & 43 & 3.91 & 20 & 10 & 78 \\
TD32 & M & 55 & 5.45 & 30 & 23 & 100 \\
\hline
\end{tabular}

965

Note. . MPU = Mean Morpheme per Utterance. $\quad$ Cl-NWR $=$ Crosslinguistic Non-word 966 Repetition. CPM = Colored Progressive Matrices.

967

968

969

970

971

972

973

974

975

976

977

978

979

980

981

982

983

984

985

986

987

988

989

990

991

992 
List of verbs used in the verb elicitation task

\begin{tabular}{|c|c|c|c|c|}
\hline \multirow[t]{2}{*}{ Pair } & \multirow{2}{*}{$\begin{array}{c}\text { Number } \\
\text { Agreement }\end{array}$} & \multirow{2}{*}{$\begin{array}{c}\text { Gender } \\
\text { Agreement }\end{array}$} & \multicolumn{2}{|c|}{ Tense } \\
\hline & & & Present (A) & Past (B) \\
\hline & \multirow{2}{*}{\multicolumn{2}{|c|}{ Practice items }} & $\begin{array}{l}\text { A. bit.qat }{ }^{\mathrm{f}} \cdot \mathrm{t}^{\mathrm{i}} \mathrm{S}^{*} \\
\text { cut-PRES-3FS }\end{array}$ & 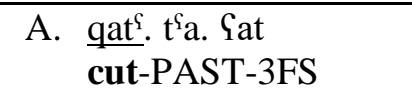 \\
\hline & & & 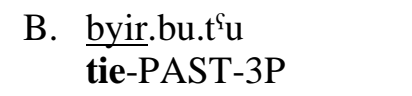 & B. $\underset{\text { tie-PA.ba } .^{\mathrm{s}} \mathrm{u}}{\text { tie-3P }}$ \\
\hline 1. & & & 1. $\frac{\text { biyo:.kil }}{\text { eat-PRES-3MS }}$ & $\begin{array}{ll}\text { 1. } & \text { ?a.kal } \\
\text { eat-PAST-3MS }\end{array}$ \\
\hline 2. & & & $\begin{array}{l}\text { 2. byif.rab } \\
\text { drink-PRES-3MS }\end{array}$ & 2. $\frac{\text { Ji.rib }}{\text { drink-PAST-3MS }}$ \\
\hline 3. & & & $\begin{array}{l}\text { 3. byi.yas.sil } \\
\text { wash-PRES-3MS }\end{array}$ & $\begin{array}{l}\text { 3. yas.sal } \\
\text { wash-PAST-3MS }\end{array}$ \\
\hline 4. & & Masculine & $\begin{array}{l}\text { 4. biy.maf. } \int i t \\
\text { brush-PRES-3MS }\end{array}$ & 4. $\frac{\text { maf. } \int a t}{\text { brush-PAST-3MS }}$ \\
\hline 5. & & & $\begin{array}{l}\text { 5. byir.sum } \\
\text { draw-PRES-3MS }\end{array}$ & 5. $\frac{\text { ra.sam }}{\text { draw-PAST-3MS }}$ \\
\hline 6. & & & $\begin{array}{l}\text { 6. byi.law.win } \\
\text { paint-PRES-3MS }\end{array}$ & $\begin{array}{l}\text { 6. law.wan } \\
\text { paint-PAST-3MS }\end{array}$ \\
\hline 7. & & & $\begin{array}{l}\text { 7. byi.yib.ri } \\
\text { sharpen- PRES-3MS }\end{array}$ & $\begin{array}{l}\text { 7. ba.ra } \\
\text { sharpen- PAST-3MS }\end{array}$ \\
\hline 8. & & & $\begin{array}{l}\text { 8. byif.taћ } \\
\text { open-PRES-3MS }\end{array}$ & 8. $\frac{\text { fa.tah }}{\text { pray-PAST-3MS }}$ \\
\hline 9. & Singular & & $\begin{array}{l}\text { 9. } \text { bit.far.fi } \\
\text { brush-PRES-3FS }\end{array}$ & 9. $\frac{\text { far.jat }}{\text { brush-PAST-3MS }}$ \\
\hline 10. & & & 10. $\frac{\text { btik.tub }}{\text { write-PRES-3FS }}$ & 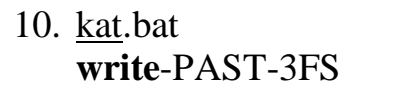 \\
\hline 11. & & & $\begin{array}{l}\text { 11. } \underline{\text { bit.qus }}{ }^{\complement} \\
\text { cut- PRES-3FS }\end{array}$ & $\begin{array}{l}\text { 11. } \underline{\text { qas }}^{\mathrm{f}} \cdot \mathrm{s}^{\mathrm{f}} \cdot \text { at } \\
\text { cut-PAST-3FS }\end{array}$ \\
\hline 12. & & Feminine & $\begin{array}{l}\text { 12. bit.naf. } \text {.jif } \\
\text { dry-PRES-3FS }\end{array}$ & 12. $\frac{\text { naf. } \int a . f a t}{\text { dry-PAST-3FS }}$ \\
\hline 13. & & & 13. $\frac{\text { bitf.rab }}{\text { drink- PRES-3FS }}$ & $\begin{array}{l}\text { 13. Jir.bit } \\
\text { drink-PAST-3FS }\end{array}$ \\
\hline 14. & & & $\begin{array}{l}\text { 14. btaf. } t^{\mathrm{s}} \mathrm{i}: \\
\text { give- PRES-3FS }\end{array}$ & 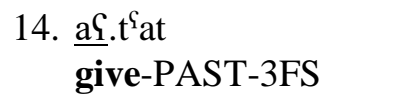 \\
\hline 15. & & & $\begin{array}{l}\text { 15. bit.ta9.mi } \\
\text { feed- PRES-3FS }\end{array}$ & $\begin{array}{l}\text { 15. taG.mat } \\
\text { feed-PAST-3FS }\end{array}$ \\
\hline .16 & & & $\begin{array}{l}\text { 16. byil.bi.su } \\
\text { wear-PRES-3PL }\end{array}$ & 16. $\underline{\text { lib.su }}$ wear-PAST-3PL \\
\hline 17. & & & $\begin{array}{l}\text { 17. byi.nad } . \text { fu } \\
\text { clean-PRES-3PL }\end{array}$ & 17. $\frac{\text { nad.d } d^{\complement} a \cdot f u}{\text { clean-PAST-3PL }}$ \\
\hline
\end{tabular}


18.

19.

20.

21.

22.

23.

24.

Plural

25.

26.

27.

28.

29.

30.
18. bif.ra.bu drink-PRES-3PL

19. byi.law.nu paint-PRES-3PL

20. byik.tu.bu write-PRES-3PL

21. byin.fu. $\chi u$ blow-PRES-3PL

22. byil.Ga.bu play-PRES-3PL

23. bin.fu.ru hang-PRES-3PL

24. byif.ta.hu open-PRES-3PL

25. byi.maf.tu brush- PRES-3PL

26. byi.far. $\int u$ brush- PRES-3PL

27. byir.bu.tu tie- PRES-3PL

28. byi.na f.fu dry- PRES-3PL

29. byi.qus $s^{\mathrm{f}} \cdot \mathrm{s}^{\mathrm{f}} \mathrm{u}$ cut- PRES-3PL

30. byif.la.hu takeoff- PRES-3PL
18. Jir.bu drink-PAST-3PL

19. law.wa.nu paint-PAST-3PL

20. ka.ta.bu write-PAST-3PL

21. na.fa. $\chi u$ blow-PAST-3PL

22. lis.bu play-PAST-3PL

23. na. fa.ru hang-PAST-3PL

24. fa.ta.hu open-PAST-3PL

25. maf. Sa.tu brush- PAST-3PL

26. far.. $\mathrm{uu}$ brush- PAST-3PL

27. ra.ba.tu tie- PAST-3PL

28. naf.ja.fu dry- PAST-3PL

29. qas $^{\complement} \cdot s^{\complement} u$ cut- PAST-3PL

30. Jil.hu takeoff- PAST-3PL

Note. PRES-3MS = present 3rd person masculine singular. PAST-3MS= past 3rd person masculine singular. PRES$3 F S=$ present 3 rd person feminine singular. PAST $-3 F S=$ past 3rd person feminine singular. $P R E S-3 P=$ present $3 r d$ person plural.PAST-3P= past 3 rd person plural. *underlined syllable are stressed. 